\title{
Errors in Diagnosing Types of Diabetes in Young Adult Patients - Constantly Valid Topic
}

\author{
Chwalba A ${ }^{1}$, Dudek $^{2 *}$ and Otto-Buczkowska $E^{3}$ \\ ${ }^{1}$ Department of Pharmacology, Medical University of Silesia, Zabrze, Poland \\ ${ }^{2}$ Inpatient Department of Radiation and Clinical Oncology, Maria Skłodowska - Curie Institute - Oncology Center, Gliwice Branch, Poland \\ ${ }^{3}$ Medical Specialist Centre in Gliwice, Poland
}

${ }^{\star}$ Corresponding author: Dudek Aleksandra, Inpatient Department of Radiation and Clinical Oncology, Maria Skłodowska - Curie Institute - Oncology Center, Gliwice Branch, Poland. Tel: +48 536299 664; E-mail: dudek.ola@op.pl

Received: March 25, 2020; Accepted: April 03, 2020; Published: April 17, 2020

\begin{abstract}
The correct differentiation of diabetes types is still a problem. This is especially true for groups of young adult patients between 20 and 55 years old. In this group of patients Type 2 diabetes is still routinely diagnosed, without a thorough analysis of the patient's history, phenotype, as well as disregarding the need to perform all necessary laboratory tests. Such diagnostic irregularities lead to taking wrong therapeutic decisions. As far as the patient's history is concerned, attention should be paid to the incidence or non-incidence of a positive history of diabetes in the patient's family. In the autoimmune diabetes such incidence usually does not occur. In Type 2 diabetes it is usually high, whereas most often it occurs on the patient's mother's and well as father's side. A feature that is usually very characteristic is high incidence on one side of the family, typical for monogenic diabetes. A very important indicator is the occurrence or non-occurrence of obesity. Clear obesity suggests the diagnosis of Type 2 diabetes, whereas in patients without obesity LADA or MODY diabetes needs to be taken into account. Conclusive in this respect are the results of tests checking the levels of C-peptide and the titre of autoantibodies, predominantly of a/GAD. When MODY diabetes is suspected, it is necessary to run genetic tests. It is extremely important to undertake efforts aiming at a correct diagnosis of the etiological cause of diabetes, i.e. determining whether we deal with the autoimmunization process, insulin resistance, or with a genetic defect, as it influences therapeutic decisions. In the presence of the autoimmunization process, it is recommended to provide the insulin therapy at an early stage. In patients with clearly marked insulin resistance an early onset of the insulin therapy should be avoided. The first choice drugs in this condition are metformin, incretin drugs, as well as drugs from the group of SGLT-2 inhibitors. In monogenic diabetes therapeutic decisions depend on the type of the genetic defect.
\end{abstract}

Keywords: diabetes, C peptide, anti-GAD antibodies, LADA diabetes, type 2 diabetes, MODY diabetes

\section{Introduction}

Differentiation of Types of diabetes has a long and still uncompleted history. After an era of regarding diabetes as a homogeneous disease, 1907 brought its differentiation into an acute and a chronic form. Over subsequent years criteria applied to the differentiation of diabetes were changing. The division in force at the moment dates back to 1999 and it differentiates four types of diabetes, that is Type 1 diabetes, Type 2 diabetes, other specific types of diabetes, and gestational diabetes mellitus.

The introduction of immunological and genetic tests broadened the possibilities of diagnosing mechanisms of glucose metabolism disorders. This is responsible for the fact that the breakdown of types of diabetes adopted so far has been becoming less and less legitimate. Still, it is a breakdown in force today [1]. Nevertheless, over subsequent years we should expect a revision of this classification [25]. In the everyday practice, when the diagnosis of diabetes is based on the clinical picture and basic laboratory tests, the determination of the type of diabetes is often erroneous [6]. According to many authors, after some time in numerous cases it is necessary to verify the initially determined type of diabetes. It refers particularly to young adults. Correct diagnostics taking into account etiological indicators allows for a more precise determination of the type of diabetes, and consequently also the selection of the correct therapy [7]. Individual types of diabetes are triggered by different mechanisms leading to these disorders. The knowledge of these mechanisms leads to therapeutic decisions. Naturally, one should take into account that performing state-of-the-art diagnostics entails an increase of costs of the diagnostic process. There are, however, many elements which may be used in the initial diagnostics without any significant cost increase.

\section{Medical History}

This stage covers an assessment of the following elements:

- Dynamics of the development of symptoms of the disease,

- Occurrence or non-occurrence of obesity,

- The patient's age,

- Positive history of diabetes in the patient's family,

- Observation of insulin demand.

Rapid accumulation of clinical symptoms is suggestive of 
autoimmunological diabetes. This refers predominantly to adolescent patients with the 'classical' Type 1 diabetes. This process develops a bit more slowly in LADA diabetes, where the course of the process of autoimmune destruction of the $\beta$ cells is fluctuate.

The occurrence or non-occurrence of obesity could be a certain indicator in the process of differentiating the types of diabetes. In Type 1 diabetes, LADA diabetes, and MODY diabetes, overweight is usually not present as of the moment of its diagnosis.

The occurrence of overweight, especially significant obesity, is characteristic for Type 2 diabetes. A diversified picture may refer to the group of secondary diabetes.

The age at which diabetes reveals itself may constitute a certain, although not final, indicator. Early manifestation of diabetes may refer to the 'classical' Type 1 diabetes, monogenic diabetes, as well as certain forms of secondary diabetes. In our latitude, rarely do we deal with Type 2 diabetes in young patients.

A positive family history of diabetes is very characteristic for monogenic diabetes, whereas in such cases it is principally on one side only. A positive family history on both sides is frequent in Type 2 diabetes. In autoimmune diabetes (Type 1 and LADA) such a family history is relatively rare.

The insulin demand can also constitute a certain indicator suggestive of the level of destruction of the $\beta$ cells and insulin resistance.

\section{Laboratory Diagnostics}

In the laboratory tests, besides the routine monitoring of glycaemia, the content of sugar and acetone in urine and the level of glycated hemoglobin $\mathrm{HbAlc}$, the possibility of determining the level of c-peptide is essential. The concentration of C-peptide in serum is used in the diagnostics of the efficiency of pancreatic islets in terms of insulin production [8-12]. Serum C-peptide concentration illustrates the function of $\beta$ cells and is useful in differentiating types of diabetes $[13,14]$. In the Type 1 diabetes, the concentration of C-peptide gets rapidly reduced and it is usually clearly lowered as of the clinical manifestation of diabetes. A different picture is presented by the level of C-peptide in the latent autoimmune diabetes of adults (LADA). Here the initial level of C-peptide as of the moment of the diagnosis is usually lowered, but it can be normal; the glucagon test, however, demonstrates the lack of the physiological increase of this level [15-17]. In Type 2 diabetes the level of C-peptide is usually elevated, especially in the early period. It is connected with the usually significant insulin resistance that accompanies this form of diabetes [18]. The level of C-peptide in this form of diabetes can get reduced in later stages of the disease, when the secondary insufficiency of the $\beta$ cells occurs. In other forms of diabetes the level of C-peptide may be different. It depends on mechanisms that lead to the disease development. In monogenic diabetes the level of C-peptide is correct [19-21]. The determination of autoantibody titers is another very important indicator in the differentiation of diabetes types. Often precise differentiation of the form of diabetes requires immunological tests. At this stage these tests should be recognised as a routine in most cases [22- 25]. Antibodies against the antigens of pancreatic islets are connected with the development of autoimmune diabetes. This category covers the 'classical' Type 1 diabetes, but also the slowly developing latent autoimmune diabetes in adults (LADA) [26, 27]. The diagnostic sensitivity of GADA and IA-2 depends on the subjects' age - at the same level of specificity. In patients aged below 40 the determination of the GADA antibodies is more useful, and in older patients - the determination of the IA-2 antibodies is more beneficial. Confirmation of a high titre of autoantibodies against the structures of pancreatic islets decides about diagnosing diabetes with autoimmune etiology (Type 1 diabetes, LADA). In Type 2 diabetes an elevated titre of antibodies is sometimes detected, as well; nevertheless, it is usually much lower than in diabetes with autoimmune aetiology and it usually soon disappears. Recently, many authors pay attention to the diverse picture of LADA diabetes. This applies to both the clinical picture and treatment options $[28,29]$. One of the ideas is to link this diversity with the patient's age at the time of LADA diabetes [30]. The assessment of the presence of autoantibodies is also useful in the differentiation of autoimmune diabetes and Type 2 diabetes in the elderly [31]. Studies in a group of 1,114 patients with LADA diabetes have shown that the type of autoantibodies is important. Presence of N-terminally truncated GAD65 autoantibodies is associated with the need for early implementation of insulin therapy [32]. In MODY diabetes the absence of the antibodies is recognised as a principle. It is established, however, that the presence of the antibodies in the group of monogenic diabetes may result from the presence of genetic defect of the $\beta$ cell, as well [33]. Sometimes the final diagnosis requires that genetic tests are run. If the presence of the autoantibodies is not detected in young patients with mild course of diabetes, the suspicion of monogenic diabetes becomes very likely. Most frequently diagnostic errors concern young adult patients.

\section{Case Studies}

Several cases are presented to illustrate the diagnostic dilemmas.

1. A25-year-old female patient, without obesity, with a negative family history of diabetes. In the patient history there was a persistent inflammation in the urethral fossa, vagina, and vulva, treated with no success. Due to deterioration of her health condition, increased thirst, and increased diuresis, the patient was admitted to hospital. At admission, the level of glucose in the blood serum was $425 \mathrm{mg} /$ $\mathrm{dl}(23.47 \mathrm{mmol} / \mathrm{l}), \mathrm{pH} 7.4$, creatinine $60 \mu \mathrm{mol} / \mathrm{l}$. After administering insulin the level of glucose in blood was reduced to $225 \mathrm{mg} / \mathrm{dl}(12.74$ $\mathrm{mmol} / \mathrm{l})$. The insulin treatment was ceased, metformin was started 3 x $500 \mathrm{mg}$. The level of C-peptide was determined to be $0.87 \mathrm{mg} / \mathrm{l}$. The patient was discharged home on the fourth day of observation with a recommendation of a follow-up visit in the Primary Care Outpatient Clinic. The type of diabetes was not determined. Recommendations included a diet and metformin therapy. During the first days after the discharge, with a strict diet and the prescribed doses of metformin, the glucose levels in self-management oscillated within the range of 127$192 \mathrm{mg} / \mathrm{dl}(7.05-10.7 \mathrm{mmol})$. The patient was referred to diabetes consultation. Due to the suspicion of the diagnosis of LADA diabetes, the autoantibodies tests was recommended, in which a very high titre of a/GAD was detected: $1080 \mathrm{IU} / \mathrm{ml}$. This confirmed the diagnosis 
of LADA diabetes. Lantus insulin in 4 units was prescribed and selfcontrol was recommended.

2. A 36-year-old male patient, without obesity. At the age of 31 the patient was diagnosed with Type 2 diabetes, treated with insulin of short effect, and then with sulfonylurea derivatives. After 5 years after the diagnosis there was a deterioration of the general health condition, the patient was referred to diabetic consultation. Due to the suspicion of the diagnosis of LADA diabetes, intensive insulin therapy was administered. The level of C-peptide was $1.26 \mathrm{ng} / \mathrm{ml}$; a/GAD > $2000 \mathrm{IU} / \mathrm{ml}, \mathrm{HbAlc} 11.5 \%$. Ophthalmological consultation revealed the occurrence of retinopathy. The suspicion of the diagnosis of LADA diabetes was confirmed.

3. A 28-year-old patient, with normal body weight. At the age of 25 he was diagnosed with Type 2 diabetes and a metformin preparation was prescribed. After 3 years, due to the deterioration of the general health condition, the patient was referred to diabetes consultation. During the consultation the level of $\mathrm{HbAlc}$ was $11.31 \%$. On the basis of the clinical picture, LADA diabetes was diagnosed. Intensive insulin therapy was started. The results of the remaining tests confirmed the diagnosis: C-peptide $0.78 \mathrm{ng} / \mathrm{ml}$; a/GAD $140 \mathrm{IU} /$ $\mathrm{ml}$.

4. A 42-year-old male patient, without obesity. At the age of 39 he was diagnosed with Type 2 diabetes. Concentration of glucose in blood was $400 \mathrm{mg} / \mathrm{dl}$; HbAlc 9.3\%. Insulin therapy was started. After reaching improvement in the test results, the insulin therapy was stopped and metformin and a sulfonylurea derivative was prescribed. After a year pharmacotherapy was stopped. 3 years after the diagnosis, due to the deterioration of his general health condition the patient was referred to diabetes consultation. Due to the suspicion of LADA diabetes, insulin and diet therapy was started. The tests performed confirmed the diagnosis of LADA diabetes. Level of C-peptide 0.69 $\mathrm{ng} / \mathrm{ml} ; \mathrm{a} / \mathrm{GAD}>2000 \mathrm{IU} / \mathrm{ml}$.

5. A 37-year-old female patient with diabetes diagnosed as Type 2 diabetes, for three years treated with insulin mixtures. The patient chronically unbalanced HbAlc $84 \%$. During the diabetes consultation a revision of the diagnosis was performed. The tests performed detected a low level of C-peptide $0.1 \mathrm{ng} / \mathrm{ml}$; a high titre of the autoantibodies a/GAD 1251.94 IU/ML, which enabled to diagnose autoimmune LADA diabetes. A high titre of a/TPO $339.1 \mathrm{IU} / \mathrm{ml}$ and an elevated titre of parietal cell antibodies. Intense insulin therapy was prescribed, with the administration of analogue insulins.

\section{Discussion}

In research carried out over recent years it was demonstrated that $5-10 \%$ of diabetes diagnosed after the age of 35 as Type 2 diabetes is in fact LADA diabetes [2, 34, 35]. Analysis of cases qualified as LADA diabetes confirms the need to perform a thorough analysis of glucose homeostasis disorders in patients aged 25-55, especially in patients without obesity and without a positive family history of diabetes [36-38]. A factor that is decisive for the differentiation process is the assessment of the titre of antibodies. An early correct diagnosis of LADA diabetes and starting insulin therapy is extremely important due to the improvement of the metabolic control, as well as due to the fact that there is much evidence that apart from the substitution activity, insulin has also immunomodulating activity, influencing the inhibition of the process of destruction of pancreatic islets [39-42]. The use of sulfonylurea derivatives in such patients is very disadvantageous, and it often results from a wrong diagnosis. In this age group it must be borne in mind that there can also occur monogenic forms of diabetes, predominantly MODY diabetes [4347]. Monogenic forms of diabetes are mainly associated with juvenile patients. Nevertheless, one needs to bear in mind that MODY diabetes can manifest itself in adults, in families where such a diagnosis has never been given before. Genetic tests are crucial in diagnosing MODY diabetes $[48,49]$. However, it may also be useful to analyze other markers, including C-peptide levels, compared to clinical picture analysis $[50,51]$. Type 2 diabetes is the form of diabetes that is still most often routinely diagnosed in adults, especially when the course of the disease is relatively mild [52]. The most common form is MODY2, which is a result of a mutation of the glucokinase gene, and MODY3 occurring due to a mutation in the HNF-1 $\alpha$ gene, which is a transcription factor subjected to expression in pancreas, liver, and kidneys [53]. A rare form of diabetes is MODY5, related to a mutation in the HNF1B gene [54-56]. This issue has been discussed in earlier publications. They present cases where MODY diabetes was diagnosed $[57,58]$. From amongst the four patients presented therein, in two patients the MODY3 type diabetes was diagnosed, MODY2 diabetes was diagnosed in one female patient, and in one male patient a rare form of MODY5 was detected. This publication also presents results of a discussion devoted to recommendations for genetic diagnostics in these syndromes.

\section{Summary}

To conclude, it should be once again emphasized how important the correctness of diagnosis of the diabetes pathogenesis is. This is decisive for the administered therapy. The most errors in the correct diagnosis pertain to the group of young adult patients. These errors result from the assessment of the patient's history and phenotype that is not thorough enough. A serious source of mistakes is neglecting the test of the level of C-peptide, as well as of the titre of anti-pancreatic antibodies, predominantly GAD. It should be remembered that in this age group all types of diabetes can occur. A wrong diagnosis of Type 2 diabetes in cases of diabetes with the autoimmune etiology is particularly frequent. However, it should be also borne in mind that it is possible that monogenic diabetes will manifest itself, too. First secondary diabetes must be always ruled out.

\section{References}

1. American Diabetes Association (2017) Classification and Diagnosis of Diabetes. Diabetes Care. 40 (Suppl 1): S11-S24.

2. Małecki M, Skupień J (2008) Problems in differential diagnosis of diabetes types. Pol Arch Med Wewn. 118:435-440.

3. Otto-Buczkowska E (2012) Diabetes - what type? Przew Lek. 15:27-32 [ISSN 15058409].

4. Thomas CC, Philipson LH (2015) Update on diabetes classification. Med Clin. North Am. 99:1-16.

5. Vionnet AC, Jornayvaz FR (2015) Classification of diabetes: an increasing heterogeneity. Rev Med Suisse. 11:1234-1237. 
6. Jachimowicz-Duda O, Zorena K, Myśliwiec M (2014) The use of low doses of longacting insulin as an effective therapy in latent autoimmune diabetes in adults - cases report. Diabet. Clin. 3, 2: 79-83.

7. Yeung RO, Hannah-Shmouni F, Niederhoffer K, Walker MA (2018) Not quite type 1 or type 2, what now? Review of monogenic, mitochondrial, and syndromic diabetes. Rev Endocr Metab Disord. Mar 19(1):35-52.

8. Jones AG, Hattersley AT (2013) The clinical utility of C-peptide measurement in the care of patients with diabetes. Diabet Med. 30:803-817.

9. Li X, Huang G, Lin J, Yang L, Zhou Z (2013) Variation of C peptide decay rate in diabetic patients with positive glutamic acid decarboxylase antibody: better discrimination with initial fasting C peptide. BMC Endocr Disord. 13:10.

10. Otto-Buczkowska E (2015) The clinical utility of C-peptide measurement in diabetology. Pediatr Endocrinol Diabetes Metab. 20:63-68.

11. Rogowicz-Frontczak A, Zozulińska-Ziółkiewicz D, Niedźwiecki P, Litwinowicz M, Wierusz-Wysocka B (2012) Does glucagon stimulation test help to predict autoimmunity in newly diagnosed non obese adults with diabetes? Exp Clin Endocrinol Diabetes. 120:428-434.

12. Stasiak T, Krzymień J, Karnafel W (2014) Clinical significance of the C peptide assay. Terapia. 22:13-16.

13. Jones AG, Shields BM, Dennis JM, Hattersley AT, McDonald TJ1, Thomas NJ1 (2020) The challenge of diagnosing type 1 diabetes in older adults. Diabet Med. Feb 11.

14. Wan M, Wang Y, Zhan L, Fan J, Hu TY (2020) MALDI-TOF mass spectrometrybased quantification of C-peptide in diabetes patients. Eur J Mass Spectrom (Chichester). 26(1):55-62.

15. Chaillous L, Bouhanick B, Kerlan V, Mathieu E, Lecomte P, Ducluzeau PH, et al. (2010) Clinical and metabolic characteristics of patients with latent autoimmune diabetes in adults (LADA): absence of rapid beta-cell loss in patients with tight metabolic control. Diabetes Metab. 36:64-70.

16. Sørgjerd EP, Skorpen F, Kvaløy K, Midthjell K, Grill V (2012) Time dynamics of autoantibodies are coupled to phenotypes and add to the heterogeneity of autoimmune diabetes in adults: the HUNT study, Norway. Diabetologia.55:1310-1318.

17. Szepietowska B, Głębocka A, Puch U, Górska M, Szelachowska M (2012) Latent autoimmune diabetes in adults in a population-based cohort of Polish patients with newly diagnosed diabetes mellitus. Arch Med Sci. 8:491-495.

18. Banu S1, Jabir NR, Manjunath CN, Shakil S, Kamal MA (2011) C-peptide and its correlation to parameters of insulin resistance in the metabolic syndrome. CNS Neurol Disord Drug Targets.10:921-927.

19. Owen KR (2013) RD Lawrence lecture 2012: assessing aetiology in diabetes: how C-peptide, CRP and fucosylation came to the party! Diabet Med. 30:260-266.

20. Owen KR (2018) Monogenic diabetes in adults: what are the new developments? Curr Opin Genet Dev. 50:103-110.

21. Thanabalasingham G, Pal A, Selwood MP, Dudley C, Fisher K, Bingley PJ, et al (2012) Systematic assessment of etiology in adults with a clinical diagnosis of youngonset type 2 diabetes is a successful strategy for identifying maturity-onset diabetes of the young. Diabetes Care. 35:1206-1212.

22. Brophy S, Davies H, Dunseath G, Stephens JW, Platts J, Lane H. et al. (2011) Experience of the introduction of routine antibody testing in primary care and of running a trial for latent autoimmune diabetes in adults (LADA). Diabetes Res Clin Pract. 93:e49-52.

23. Garnier L, Marchand L, Benoit M, Nicolino M, Bendelac N, Wright C. et al. (2018) Screening of ZnT8 autoantibodies in the diagnosis of autoimmune diabetes in a large French cohort. Clin Chim Acta. 478:162-165.

24. Sørgjerd EP (2019) Type 1 Diabetes-related Autoantibodies in Different Forms of Diabetes. Curr Diabetes Rev. 15(3):199-204.

25. Zhang S, Sun Q, Feng K, Fu Y, Wang O, Ping F, Li Y (2012) Clinical, biochemical, and immunological characteristics of newly diagnosed nonobese diabetic patients aged 18-45 years in China. J Diabetes Complications. 26:40

26. Hawa MI, Kolb H, Schloot N, Beyan H, Paschou SA, Buzzetti R. et al. (2013) Action LADA consortium. Adult-onset autoimmune diabetes in Europe is prevalent with a broad clinical phenotype: Action LADA 7. Diabetes Care. Apr 36(4):908-913.

27. Otto-Buczkowska E (2013) Type LADA diabetes - interrogation points. Przegl Lek. 70:25-27 [ISSN 1641-6565] [ICID: 1037026].
28. Liang H, Cheng Y, Tang W, Cui Q, Yuan J, Huang G, et al. (2019) Clinical manifestation and islet $\beta$-cell function of a subtype of latent autoimmune diabetes in adults (LADA): positive for $\mathrm{T}$ cell responses in phenotypic type 2 diabetes. Acta Diabetol. 56(11):1225-1230.

29. Pozzilli P, Pieralice S (2018) Latent Autoimmune Diabetes in Adults: Current Status and New Horizons. Endocrinol Metab (Seoul). 33(2):147-159.

30. Niu X, Luo S, Li X, Xie Z, Xiang Y, Huang G. et al.( 2019) Identification of a distinct phenotype of elderly latent autoimmune diabetes in adults: LADA China Study 8 . Diabetes Metab Res Rev. 35(1):e3068.

31. Yohena S, Penas-Steinhardt A, Muller C, Faccinetti NI, Cerrone GE, Lovecchio S et al.(2019) Immunological and clinical characteristics of latent autoimmune diabetes in the elderly. Diabetes Metab Res Rev. 35(5):e3137.

32. Achenbach P, Hawa MI, Krause S6, Lampasona V, Jerram ST, Williams AJK et al (2018) Action LADA consortium. Autoantibodies to N-terminally truncated GAD improve clinical phenotyping of individuals with adult-onset diabetes: Action LADA 12. Diabetologia. 61(7):1644-1649.

33. McDonald TJ, Colclough K, Brown R, Shields B, Shepherd M, Bingley P, et al. (2011) Islet autoantibodies can discriminate maturity-onset diabetes of the young (MODY) from Type 1 diabetes. Diabet Med. 28:1028-1033.

34. Carlsson S (2019) Etiology and Pathogenesis of Latent Autoimmune Diabetes in Adults (LADA) Compared to Type 2 Diabetes. Front Physiol.10:320.

35. Naik R G, Brooks-Worrell B M, Palmer J P (2009) Latent autoimmune diabetes in adults. J. Clin. Endocrinol. Metab. 94: 4635-4644.

36. Chwalba A, Otto-Buczkowska E (2015) Type LADA diabetes - still even diagnostic problem in general practice. Med. Metabol. 19:34-40 [ISSN 1428-1430].

37. Grill V, Åsvold BO (2019) A form of Autoimmune Diabetes in Adults Named LADA - An Update on Essential Features and Controversies. Curr Diabetes Rev. 15 (3):172-173.

38. Otto-Buczkowska E, Marciniak-Brzezińska M (2013) Type LADA diabetes - what does his mean? Med. Rodz. 16:23-26 [ISSN 1505-3768]

39. Cernea S, Buzetti R, Pozzilli P (2009) Beta-cell protection and therapy for latent autoimmune diabetes in adults. Diabetes Care. 32 Suppl 2:S246-52.

40. Liu B, Xiang Y, Liu Z, Zhou Z (2020) Past, present and future of latent autoimmune diabetes in adults. Diabetes Metab Res Rev. 36(1):e3205.

41. Pieralice S, Pozzilli P (2018) Latent Autoimmune Diabetes in Adults: A Review on Clinical Implications and Management. Diabetes Metab J. Dec 42(6):451-464.

42. Poudel R R (2012) Latent autoimmune diabetes of adults: From oral hypoglycemic agents to early insulin. Indian J. Endocrinol. Metab. 16 (supl. 1): S41-S46.

43. Borowiec M, Fendler W, Antosik K, Ciepiela A, Baranowska A, Hogendorf A. et al. (2010) Optimization of monogenic diabetes screening programme--initial report on recruitment efficacy of the TEAM project. Pediatr Endocrinol Diabetes Metab. 16:7376.

44. Fendler W, Małachowska B, Baranowska-Jazwiecka A, Borowiec M, Wyka K, Maleck MT. et al. (2014) PolPeDiab Study Group. Population-based estimates for double diabetes amongst people with glucokinase monogenic diabetes, GCK-MODY. Diabet Med. 31:881-883.

45. Gaál Z, Balogh I (2019) Monogenic Forms of Diabetes Mellitus. Exp Suppl. 111:385416 .

46. Małachowska B, Borowiec M, Antosik K, Michalak A, Baranowska-Jaźwiecka A, Deja G. et al. (2018) Monogenic diabetes prevalence among Polish children-Summary of 11 years-long nationwide genetic screening program. Pediatr Diabetes. 19(1):53-58.

47. Schwitzgebel VM (2014) Many faces of monogenic diabetes. J Diabetes Investig. 5: 121-133.

48. Wang X, Wang T, Yu M, Zhang H, Ping F, Zhang Q. et al. (2019) Screening of HNF1A and HNF4A mutation and clinical phenotype analysis in a large cohort of Chinese patients with maturity-onset diabetes of the young. Acta Diabetol. 56(3):281-288.

49. Wędrychowicz A, Tobór E, Wilk M, Ziółkowska-Ledwith E, Rams A, Wzorek K. et al. (2017) Phenotype Heterogeneity in Glucokinase-Maturity-Onset Diabetes of the Young (GCK-MODY) Patients. J Clin Res Pediatr Endocrinol. 9(3):246-252.

50. Fu J, Wang T, Liu J, Wang X, Zhang Q, Li M, Xiao X (2019) Using Clinical Indices to Distinguish MODY2 (GCK Mutation) and MODY3 (HNF1A Mutation) from Type 1 Diabetes in a Young Chinese Population. Diabetes Ther. Aug 10(4):1381-1390. 
Dudek A (2020) Errors in Diagnosing Types of Diabetes in Young Adult Patients - Constantly Valid Topic.

51. Szopa M, Klupa T, Kapusta M, Matejko B, Ucieklak D, Glodzik W. et al. (2019) A decision algorithm to identify patients with high probability of monogenic diabetes due to HNF1A mutations. Endocrine. 64(1):75-81.

52. Biesecker LG (2018) Genomic screening for monogenic forms of diabetes. BMC Med. 16(1):25.

53. Pinés Corrales PJ, López Garrido MP, Louhibi Rubio L, Aznar Rodríguez S, López Jiménez LM, Lamas Oliveira C. et al. (2011) Importance of clinical variables in the diagnosis of MODY2 and MODY3. Endocrinol Nutr. 58:341-346.

54. Clissold RL, Hamilton AJ, Hattersley AT, Ellard S, Bingham C (2015) HNF1Bassociated renal and extra-renal disease-an expanding clinical spectrum. Nat Rev Nephrol. 11:102-112.
55. Musetti C, Quaglia M, Mellone S, Pagani A, Fusco I, Monzani A. et al. (2014) Chronic renal failure of unknown origin is caused by HNF1B mutations in $9 \%$ of adult patients: a single centre cohort analysis. Nephrology (Carlton). 19:202-209.

56. Raaijmakers A, Corveleyn A, Devriendt K, van Tienoven TP, Allegaert K, Van Dyck M. et al. (2015) Criteria for HNF1B analysis in patients with congenital abnormalities of kidney and urinary tract. Nephrol Dial Transplant. 30:835-842.

57. Otto-Buczkowska E, Marciniak-Brzezińska M (2015) Mody (maturity onset diabetes of the young) should be also considered in adult persons, casual presentation. Med Metabol 19:25-28 [ISSN 1428-1430].

58. Otto-Buczkowska E, Stańczyk J (2015) About MODY (Maturity onset diabetes of the young) one should also think in adults patients - Complementary causal description (II). Med. Metabol 19:41-43 [ISSN 1428-1430]. 